\title{
Recent Advances in the Diagnosis of Tuberculosis
}

\author{
Kusum Sharma, Suma B Appannanavar, Kapil Goyal, Aman Sharma
}

\begin{abstract}
Tuberculosis is an important health problem requiring early diagnosis for timely initiation of therapy and control of disease transmission. Though, conventional techniques, such as detection of acid fast bacilli by Ziehl-Neelsen staining, are very economical, yet have a low sensitivity. Isolation of mycobacteria by culture on Lowenstein Jensen media, considered to be the gold standard, is not only time consuming but has a low sensitivity, especially in extrapulmonary tuberculosis. Recent advances in molecular techniques have revolutionized the diagnostic microbiology. Various new modalities in the diagnosis of tuberculosis, like LED microscopy, microscopically observed drug susceptibility testing (MODS), antigen detection tests along with various molecular methods, like loop mediated isothermal amplification (LAMP), multiplex PCR and Xpert MTB/RIF, are discussed in the present review.
\end{abstract}

Keywords: Tuberculosis, LED microscopy, BACTEC MGIT culture, LIne probe assay, MODS, In-house PCR, Xpert MTB/RIF

How to cite this article: Sharma K, Appannanavar SB, Goyal K, Sharma A. Recent Advances in the Diagnosis of Tuberculosis. J Postgrad Med Edu Res 2013;47(4):181-187.

Source of support: Nil

Conflict of interest: None declared

\section{INTRODUCTION}

Tuberculosis (TB) is a major public health problem worldwide and according to World Health Organization (WHO), India, accounts for one-fifth of this global burden of TB. ${ }^{1}$ Prompt and accurate diagnosis is of paramount importance both for better patient outcome and for control of disease. Past few decades have witnessed a tremendous improvement in the modalities available for the diagnosis of tuberculosis with the introduction of newer microscopic, culture and molecular methods. Though conventional microscopy is the backbone of tuberculosis control programs, yet is limited by low sensitivity. ${ }^{2}$ Even culture, which is considered to be a gold standard is inadequate due to slow turnaround time and low sensitivity. ${ }^{3}$ Diagnosis of tuberculosis is a challenging task, especially in paucibacillary conditions, including extrapulmonary cases, HIV patients and pediatric population. Major problems in HIV patients arise because of smear negativity due to low bacillary load. This low bacillary load has been attributed to noncavitary lesions in HIV patients, like miliary TB pneumonia or Lymph Node TB. In pediatric population, the major limiting factor is the difficulty in sample collection. ${ }^{4}$ Thus, there is a need for rapid, sensitive and specific test for diagnosis of both pulmonary and extrapulmonary conditions. ${ }^{5}$
Additionally, drug-resistant tuberculosis including multidrug (MDR-TB) and extensively drug resistant TB (XDRTB) are on the rise. Early detection and treatment of these cases is a primary goal in minimizing the spread. Conventional antimycobacterial susceptibility testing (proportion method) is a time consuming procedure, so a rapid detection of drug resistant tuberculosis is the need of the hour. ${ }^{6,7}$

Nontuberculous mycobacteria (NTM) are not only being increasingly recognized as pathogenic in immunocompromised or transplant patients but also are being increasingly reported in immunocompetent individuals. This has been possible due to the availability of improved diagnostic modalities. ${ }^{8}$ The clinical presentation of NTM is often hard to differentiate from that of MTBC; therefore, it is important to accurately identify NTM for the timely and proper treatment of these patients. ${ }^{9}$

In the present review, we are going to highlight the latest development in diagnostic modalities for tuberculosis, including advances in microscopy, culture techniques along with brief description of molecular techniques being used in the diagnosis of tuberculosis.

\section{MICROSCOPY}

Conventional microscopy using Ziehl-Neelsen staining is a rapid and cost-effective way of detecting tubercular bacilli but lacks sensitivity. Lower sensitivity is encountered in pediatric TB, extrapulmonary TB and in HIV-infected TB patients. ${ }^{2}$ Conventional fluorescence microscopy is more sensitive than Ziehl-Neelsen staining and takes less time. ${ }^{10}$ It is $10 \%$ more sensitive as compared to conventional microscopy. ${ }^{11}$ But, its use has been limited by the high cost of the fluorescent microscope due to which it is available at few referral laboratories.

\section{Recent Advances in Microscopy}

Light-emitting diodes (LED) have been developed to offer the benefits of fluorescent microscopy without the associated costs. According to WHO, LED microscopy is more sensitive than conventional light microscopy and has a qualitative, operational and cost advantages over both conventional fluorescence and light microscopy. ${ }^{10}$ According to a study by Shenai et al, LED microscopy had sensitivity of $78.3 \%$ and specificity of $92.0 \%$ for diagnosis of pulmonary specimens and sensitivity of $34.0 \%$ and specificity of $88.8 \%$ for extrapulmonary specimens. The mean time per smear examination is 1.41 minute for LED microscopy as compared to 2.48 minutes for $\mathrm{ZN}$ stain. Thus, 
it has significant benefits over both $\mathrm{ZN}$ microscopy and conventional FM. Adequate training and detailed standard operating procedures are required to maximize accuracy. ${ }^{12,13}$

\section{ADVANCES IN CULTURE METHODS}

\section{BACTEC MGIT 960 Culture System}

The BACTEC MGIT 960 culture system is a fluorescent signalling system for earlier detection of growth. ${ }^{14}$ MGIT has several advantages over the BACTEC 460 TB system (radiometric system). It provides an early recovery of Mycobacterium, i.e. within 10 days as compared to 24 to 28 days by conventional culture methods and drug susceptibility can be checked in shorter time span. ${ }^{14}$ The major limitation is high cost of equipment and availability only at limited tertiary care centers.

\section{MODS (Microscopic-Observation Drug-Susceptibility) Assay}

The MODS assay addresses two key gaps in resource-limited settings with a high tuberculosis burden: rapid and accurate detection of $M$. tuberculosis and simultaneous drug susceptibility testing. ${ }^{15}$ It is based on three principles: first; $M$. tuberculosis grows faster in liquid medium, second; characteristic cord formation can be visualized microscopically, third; the incorporation of drugs permits rapid and direct drug-susceptibility testing concomitantly with the detection of bacterial growth. ${ }^{15}$ It has several advantages as it requires only an inverted light microscope, whereas automated mycobacterial culture requires computer-linked automated culture incubators which are expensive. Only disadvantage of MODS is bacterial contamination, especially with aerobic spore bearers due to highly enriched medium. ${ }^{16}$

In a meta-analysis of 12 studies, Minion et al have shown a pooled sensitivity of $92 \%$ and specificity of $96 \%$ for MODS in the detection of M. tuberculosis (Table 1). The average contamination rate was around $6.6 \%$ for MODS and the turnaround time was 9.2 days. Thus, MODS is an inexpensive, rapid alternative to conventional method for drug susceptibility testing of $M$. tuberculosis. The current available data supports WHO's recommendation for use of selected noncommercial drug-susceptibility tests, including
MODS, as an interim solution until capacity for genotypic or automated liquid culture drug susceptibility testing is developed. ${ }^{17}$

\section{ANTIGEN DETECTION METHODS}

Tests that detect $M$. tuberculosis antigens in clinical specimens could provide rapid direct evidence of infection. Most frequently targeted antigen is Lipoarabinomannan (LAM). For pulmonary TB, sensitivity estimates ranged from 2 to $100 \%$ and specificity from 33 to $100 \%$. The pooled sensitivity of urine LAM was higher in HIV-infected than HIV-uninfected individuals (47\% vs 14\%); pooled specificity estimates were similar: 96 and $97 \%$ respectively. For extrapulmonary TB, sensitivity estimates ranged from 0 to $100 \%$ and specificity estimates from 62 to $100 \%$. Before one can use antigen detection tests as a rapid pointof-care test, research to improve their performance is urgently needed. ${ }^{26}$

\section{MOLECULAR METHODS}

Nucleic acid amplification methods have revolutionized the diagnostic microbiology. NAATs are the most promising development for rapid diagnosis of $\mathrm{TB}$ and rapid drugsusceptibility testing. For M. tuberculosis, a number of nucleic acid amplification techniques are available as commercial or in-house tests. The examples of commercially available amplification methods using various targets is summarized in Table 2.

Besides, being costly, commercially available NAATs suffer from low sensitivity in smear negative cases and also in extrapulmonary tuberculosis. These tests have a good sensitivity only in smear positive sputum samples. ${ }^{36}$

\section{In-house PCR}

Sensitivity of in-house polymerare chain reation (PCR) is variable ranging from 45 to $95 \%$. Various targets had been used for diagnosis of tuberculosis including, $38 \mathrm{kDa}$, devR, IS6110 and MPB64. There is heterogeneity in results of in-house PCR. The reasons for heterogeneity are, sample volume, presence of inhibitors, DNA extraction protocol, smear positive vs smear negative cases, pulmonary $v s$ extrapulmonary TB (paucibacillary) and uniplex $v s$

\begin{tabular}{clccc}
\multicolumn{6}{c}{ Table 1: The sensitivity and specificity of MODS test in the diagnosis of pulmonary tuberculosis } \\
\hline S. no. & Region & Sputum samples $(n)$ & Sensitivity (\%) & Specificity (\%) \\
\hline 1 & Vietnam & 709 & 77 & 99 \\
2 & India & 302 & 94 & 89 \\
3 & India & 105 & 92 & 98 \\
4 & China & 275 & 90 & 96 \\
5 & South Africa & 534 & 85 & 97 \\
6 & Peru & 120 & 91 & 21 \\
7 & India & 171 & 98 & 22 \\
8 & Vietnam & 738 & 87 & 99 \\
\hline
\end{tabular}


multiplex PCR protocols. Uniplex PCR targets the single target whereas multiplex PCR targets more than one target in a single reaction mixture. Most commonly used target in uniplex PCR is insertion sequence IS6110 as it is present in multiple copy number but it is absent in 10 to $40 \%$ of Indian isolates of $M$. tuberculosis. In tuberculous meningitis patients, we have also evaluated the $38 \mathrm{kDa}$ primer with a sensitivity and specificity of 83 and $100 \%$ respectively. Multiplex PCR has number of advantages as compared to uniplex PCR. Multiplex PCR is more sensitive and specific. ${ }^{37}$ In our own experience, we have seen that targeting more than one site, i.e. site other than IS6110, greatly enhances the sensitivity of multiplex PCR. We have evaluated multiplex PCR using protein-b, MPB 64 and IS6110 primers directed against $M$. tuberculosis complex for the diagnosis of tuberculous meningitis (TBM). The multiplex PCR showed a high sensitivity of $86.63 \%$ and specificity of $100 \%$ as compared to conventional methods. ${ }^{38}$ In osteoarticular tuberculosis, also, multiplex targeting IS6110 and MPB 64 showed a high sensitivity of 100\% in confirmed cases and $81.8 \%$ in clinically suspected cases with a specificity of $100 \% .{ }^{39}$ Thus, multiplex PCR is more sensitive as compared to uniplex PCR and can be carried out in resource limiting countries where commercially available NAATs are still very far from the reach of routine diagnostic laboratories. We also have noted a high sensitivity and specificity for MPCR in other extrapulmonary conditions, like ocular TB, gastrointestinal TB, lymph node TB and female genital tract TB. ${ }^{40-42}$

Molecular techniques, like PCR, are being used for the detection of NTM with increased sensitivity and specificity. Bhattacharya et $\mathrm{al}^{43}$ developed a multiplex PCR based on amplification of 165, 365 and 541 bp target fragments of unrelated genes, hsp 65 coding for $65 \mathrm{kDa}$ antigen, dnaJ gene of mycobacteria and insertion element IS6110 of M. tuberculosis, respectively. This multiplex PCR was tested over 5 years from 1996 to 2001 with 411 clinical specimens from suspected cases of tuberculosis and mycobacterioses and compared with standard laboratory techniques. The multiplex PCR was positive for 379 cases compared with 280 cases by standard techniques $(\mathrm{p}<0.0001)$. It could distinguish between strains of the $M$. tuberculosis complex and NTM; the results are comparable with standard techniques. Thus, the multiplex PCR can be useful in early detection, species differentiation and epidemiology. In our laboratory, we have standardized multitargeted PCR for rapid diagnosis of $M$. tuberculosis and $M$. avium. By using this method, we have reported for the first time from our centre a coinfection of $M$. tuberculosis and $M$. avium in HIV positive patient. ${ }^{44}$

Loop mediated isothermal amplification (LAMP) is an isothermal amplification technique which can amplify the target region rapidly and efficiently. It can be carried out in a simple water bath and relies on auto-cycling strand displacement DNA synthesis by a Bst DNA polymerase. The large amount of DNA generated in less than an hour and positive LAMP reaction can be visualized with the naked eye by adding $0.1 \%$ SYBR Green to the tube and observing the color of the solution under UV light. The solution turns green in the presence of a LAMP amplicon, while it remains orange in the absence of amplification. The previous studies have shown a good sensitivity and specificity of 88 to $100 \%$ and 94 to $100 \%$ respectively. ${ }^{29,45,46}$ LAMP has several advantages: does not require thermocycler, is rapid, simple and cost-effective method for diagnosis in resource limited setting.

\section{Xpert MTB/RIF}

To respond to the urgent need for simple and rapid diagnostic tools at the point of care in high-burden countries, a fully automated $\left(\mathrm{Xpert}^{\circledR}\right.$ MTB/RIF) molecular test for tuberculosis case detection and drug-resistance testing has been developed. The Xpert ${ }^{\circledR}$ MTB/RIF purifies, concentrates, amplifies (by real-time PCR) and identifies targeted nucleic acid sequences in the TB genome. The Xpert MTB/RIF detects $M$. tuberculosis (MTB) and resistance to rifampin (RIF) using heminested real-time polymerase-chain-reaction (PCR) assay by amplifying MTB-specific sequence of the rpoB gene, which is probed with molecular beacons for mutations within the rifampin-resistance determining region. It provides results from unprocessed sputum samples in 90 minutes, with minimal biohazard and very little technical training is required to operate the machine. MTB/RIF test correctly detected rifampin resistance with a sensitivity of $99.1 \%$ and specificity of $100 \% .{ }^{47}$ Vadwai et al evaluated extrapulmonary specimens which were split and processed

Table 2: Performance of commercial kits in direct detection of MTB by nucleic acid amplification using different targets

\begin{tabular}{llccc}
\hline Nucleic acid target & Test name & Sensitivity (\%) & Sensitivity (\%) & References \\
& & Smear positive & NA & $27-29$ \\
\hline 16S rRNA & Cobas Amplicor MTB & $91.7-95.2$ & 72 & 30 \\
Antigen b & LCx & $92.1-96.7$ & NA & 31 \\
23S rRNA & NucliSens QT & $91.1-95.8$ & $40.3-53.1$ & 32,33 \\
IS6110 & BD-Probe Tec ET & $92.1-98.5$ & NA & 34,35 \\
16S rRNA & Cobas TaqMan MTB & 71.0 & & \\
\hline
\end{tabular}


simultaneously for both culture (solid and liquid) and Xpert testing. ${ }^{48}$ The sensitivity of the Xpert assay was $81 \%(64 \%$ for smear-negative cases and $96 \%$ for smear-positive cases), with a specificity of $99.6 \%$ (Tables 3 and 4). The sensitivity was found to be high for the majority of specimen types (63 to 100\%) except for cerebrospinal fluid, the sensitivity of which was $29 \%$. The Xpert test correctly identified $98 \%$ of phenotypic rifampin (RIF)-resistant cases and 94\% of phenotypic RIF-susceptible cases. Thus, Xpert test has so far shown good potentials for the diagnosis of both pulmonary and extrapulmonary TB and is suitable for TB endemic countries.

Currently, the major hindrance is its high cost, instrument alone costs approximately 17,000 US \$. However, to expand its adoption in developing countries, Foundation for innovative new diagnostics (FIND) and other agencies have announced their agreement to significantly reduce the cost of this rapid TB diagnostic tool in 145 high-burden countries including India. Cost of single cartridge would be around 9.98 US \$/test.

\section{Molecular Line Probe Assays}

Novel technologies for rapid detection of anti-TB drug resistance are the need of the hour. Molecular line probe assays focused on rapid detection of rifampicin resistance (alone or in combination with isoniazid). The most effectively studied commercial molecular line probe assays are (1) INNO-LiPA Rif.TB kit-Innogenetics, Zwijndrecht, Belgium, (2) genotype MTBDR and genotype MTBDRplus
assay-Hain Lifescience, Germany. Both of these assays are PCR-based and detect $M$. tuberculosis complex and specific mutations in the rpoB gene conferring rifampicin resistance. The genotype MTBDRplus assay also simultaneously detects specific mutations in the katG gene conferring high-level isoniazid resistance as well as those in the inhA gene conferring low-level isoniazid resistance. INNO-LiPA Rif.TB kit is labelled for use on M. tuberculosis isolates grown on solid culture. While, genotype MTBDR and genotype MTBDRplus assays are labelled for use on isolates from solid and liquid culture as well as directly on smear-positive pulmonary specimens. ${ }^{49}$

In a systematic review and meta-analysis, to evaluate the accuracy of LiPA for the detection of rifampicin-resistant tuberculosis among culture isolates and clinical specimens Morgan et al included 15 studies that met inclusion criteria in literature search. Of these, 11 studies used culture isolates, one used clinical specimens, and three used both. A summary receiver operating characteristics (sROC) analysis is a statistical technique that can be applied to meta-analysis of diagnostic tests. The sROC curve is initially constructed by plotting the sensitivity (true positivity) and false positivity (1-specificity) of each study. There are three commonly used methods to assess the accuracy of the test: the exact area under the curve (AUC) for the sROC function, the homogeneous AUC, and the index Q*. A test close to ideal an index $Q^{*}$ close to 1 . In contrast, a test of poor discriminatory ability has an index $\mathrm{Q}^{*}$ close to 0.5 . LiPA is a highly sensitive and specific test for the detection of rifampicin

\begin{tabular}{|c|c|c|c|c|c|c|}
\hline \multirow[t]{2}{*}{ Region } & \multicolumn{3}{|c|}{ Sensitivity } & \multirow[t]{2}{*}{ Specificity } & \multirow[t]{2}{*}{$P P V$} & \multirow[t]{2}{*}{$N P V$} \\
\hline & $\begin{array}{l}\text { All culture } \\
\text { positive }\end{array}$ & $\begin{array}{l}\text { Sputum positive, } \\
\text { culture positive }\end{array}$ & $\begin{array}{l}\text { Sputum negative, } \\
\text { culture positive }\end{array}$ & & & \\
\hline Lima, Peru & $96.6 \%$ & $99.3 \%$ & $88.1 \%$ & $99.6 \%$ & $98.0 \%$ & $99.3 \%$ \\
\hline Baku, Azerbaijan & $88.6 \%$ & $97.8 \%$ & $74.7 \%$ & $98.7 \%$ & $97.6 \%$ & $93.5 \%$ \\
\hline Cape Town, South Africa & $86.3 \%$ & $100 \%$ & $79.1 \%$ & $99.7 \%$ & $99.0 \%$ & $95.6 \%$ \\
\hline Kampala, Uganda & $83.4 \%$ & $97.8 \%$ & $57.7 \%$ & $100 \%$ & $100 \%$ & $87.7 \%$ \\
\hline Vellore, India & $100 \%$ & $100 \%$ & $100 \%$ & $97.7 \%$ & $85.8 \%$ & $100 \%$ \\
\hline Manila, Philippines & $91.9 \%$ & $96.2 \%$ & $56.3 \%$ & $97.9 \%$ & $95.7 \%$ & $95.9 \%$ \\
\hline Total & $90.3 \%$ & $98.3 \%$ & $76.9 \%$ & $99.0 \%$ & $96.8 \%$ & $96.8 \%$ \\
\hline
\end{tabular}

Sensitivity, specificity and predictive values of direct MTB/RIF test (Adapted from Lancet 2011;377:1495-1505)

\begin{tabular}{lccc}
\multicolumn{2}{c}{ Table 4: Sensitivity of Xpert MTB/RIF assay in HIV negative and HIV positive samples } \\
\hline & HIV positive & HIV negative & HIV status unknown \\
\hline Sensitivity in culture-positive samples & & & $72.3 \%$ \\
Smear microscopy & $44.6 \%$ & $68.6 \%$ & $92.3 \%$ \\
MTB/RIF test & $82.4 \%$ & $90.7 \%$ & $98.4 \%$ \\
Sputum positive & $97.7 \%$ & $99.0 \%$ & $79.3 \%$ \\
Sputum negative & $71.8 \%$ & $77.5 \%$ & $99.4 \%$ \\
Specificity in non-tuberculosis samples & $100 \%$ & $99.4 \%$ & $98.9 \%$ \\
Smear microscopy & $99.2 \%$ & $99.3 \%$ & \\
MTB/RIF test & &
\end{tabular}

Sensitivity, specificity and predictive values of direct MTB/RIF test (Adapted from Lancet 2011;377:1495-1505) 


\begin{tabular}{|c|c|c|c|c|c|c|}
\hline S. no. & Country & Isolates/clinical samples(n) & Sensitivity (\%) & Specificity (\%) & Concordance (\%) & References \\
\hline 1 & Latvia & $C^{*}(107)$ & 96 & NA & NA & 51 \\
\hline 5 & Kuwait & $\mathrm{I}(80)$ & NA & NA & 95 & 52 \\
\hline 6 & Turkey & I(60) & 98 & NA & NA & 53 \\
\hline 8 & Portugal & $\mathrm{I}(113)$ & 91 & 98 & NA & 54 \\
\hline 9 & Turkey & $I^{*}(65)$ & NA & NA & 96 & 55 \\
\hline 10 & Rwanda & $\mathrm{C}(3763)$ & 69 & 98 & NA & 56 \\
\hline 11 & Belgium & $C(420)$ & NA & NA & 99 & 57 \\
\hline 12 & United Kingdom & C(1997) & 95 & 99 & 99 & 58 \\
\hline 13 & Finland & $\mathrm{I}(52)$ & NA & NA & 98 & 59 \\
\hline 14 & Portugal & $C^{*}(360)$ & 100 & 96 & NA & 60 \\
\hline 15 & Denmark & $\mathrm{C}(60)$ & 78 & NA & 100 & 61 \\
\hline 16 & Italy & $\mathrm{C}(88)$ & NA & NA & 100 & 62 \\
\hline 17 & India & $\mathrm{I}(55)$ & 60 & NA & NA & 63 \\
\hline 19 & India & $1(36)$ & NA & NA & 100 & 64 \\
\hline
\end{tabular}

C: clinical sample; I: isolates; NA: not available; $C^{*}$ : smear positive clinical samples; ${ }^{*}$ : rifampicin resistant isolates

resistance in culture isolates. The test appears to have relatively lower sensitivity when used directly on clinical specimens. ${ }^{50}$ Table 5 shows recent studies that have evaluated commercial line probe assays.

Mycobacterial strain typing is important, both for the analysis of the spread of tuberculosis and for monitoring the development of antibiotic resistance. Molecular fingerprinting of M. tuberculosis is particularly challenging due to its clonal nature. Development of rapid typing methods remains important, and alternative PCR-based techniques are particularly promising, as they may facilitate both rapid diagnosis and molecular typing of tuberculosis. Repeat amplification by using the conventional IS6110RFLP typing has been supplemented by PCR-based methods, such as spoligotyping and double-repetitiveelement (DRE)-typing. Other typing techniques MIRU-VNTR (mycobacterial interspersed repetitive units-variable number of tandem repeats) are being increasingly used for typing.

\section{UREASE BREATH TEST FOR RAPID DIAGNOSIS OF TB}

Metabolic pathway detection may provide rapid and effective new tools for TB that can improve TB diagnostics for children and HIV-infected patients. Metabolic breath tests have advantages because these are safe and rapid tool for drug efficacy evaluation during clinical trials. The signal correlated with bacterial load both for primary diagnostics and treatment monitoring. Clinical trials are currently ongoing. Urea breath testing may provide a useful diagnostic and biomarker assay for tuberculosis and treatment response.

\section{CONCLUSION}

Rapid and accurate diagnosis of $M$. tuberculosis infection and drug susceptibility testing is now possible due to the availability of various new diagnostic modalities, including LED microscopy, BACTEC mycobacteria growth indicator tube (MGIT) culture technique, and molecular assays. PCR is now being incorporated as routine diagnostic test in tertiary care centers. Despite availability of these techniques, there is still a need to develop a rapid and accurate point of care test which is highly required for the diagnosis of tuberculosis at the community level.

\section{REFERENCES}

1. WHO annual report on global TB control—summary. Wkly Epidemiol Rec 2003;11;78(15):122-128.

2. Lodha R, Kabra SK, Seth V. Diagnosis of tuberculosis. Indian J Pediatr 2000;67(2 Suppl):S3-8.

3. Sharma SK, Mohan A. Extrapulmonary tuberculosis. Indian J Med Res 2004;120(4):316-353.

4. Marais BJ. Childhood tuberculosis: epidemiology and natural history of disease. Indian J Pediatr 2011;78(3):321-327.

5. Rockwood RR. Extrapulmonary TB: what you need to know. Nurse Pract 2007;32(8):44-49.

6. Zager EM, McNerney R. Multidrug-resistant tuberculosis. BMC Infect Dis 2008;8:10.

7. Vincent V, Rigouts L, Nduwamahoro E, Holmes B, Cunningham J, Guillerm M, et al. The TDR tuberculosis strain bank: a resource for basic science, tool development and diagnostic services. Int J Tuberc Lung Dis 2012;16(1):24-31.

8. Shojaei H, Heidarieh P, Hashemi A, Feizabadi MM, Daei Naser A. Species identification of neglected nontuberculous mycobacteria in a developing country. Jpn J Infect Dis 2011; 64(4):265-71.

9. Tortoli E, Benedetti M, Fontanelli A, Simonetti MT. Evaluation of automated BACTEC MGIT 960 system for testing susceptibility of Mycobacterium tuberculosis to four major antituberculous drugs: comparison with the radiometric BACTEC 460TB method and the agar plate method of proportion. J Clin Microbiol 2002;40(2):607-610.

10. Lehman LG, Ngapmen Yamadji AL, Ngo Sack F, Bilong Bilong $\mathrm{CF}$. The CyScope(R) fluorescence microscope, a reliable tool for tuberculosis diagnosis in resource-limited settings. Am J Trop Med Hyg 2010;83(4):906-908.

11. Steingart KR, Henry M, Ng V, Hopewell PC, Ramsay A, Cunningham J, et al. Fluorescence versus conventional sputum smear microscopy for tuberculosis: a systematic review. Lancet Infect Dis 2006;6(9):570-581. 
12. Shenai S, Minion J, Vadwai V, Tipnis T, Shetty S, Salvi A, et al. Evaluation of light emitting diode-based fluorescence microscopy for the detection of mycobacteria in a tuberculosisendemic region. Int J Tuber Lung Dis 2011;15(4):483-488.

13. Anthony RM, Kolk AH, Kuijper S, Klatser PR. Light emitting diodes for auramine $\mathrm{O}$ fluorescence microscopic screening of Mycobacterium tuberculosis. Int J Tuber Lung Dis 2006;10(9): 1060-1062.

14. Rodrigues C, Shenai S, Sadani M, Sukhadia N, Jani M, Ajbani K, et al. Evaluation of the bactec MGIT $960 \mathrm{~TB}$ system for recovery and identification of Mycobacterium tuberculosis complex in a high through put tertiary care centre. Indian J Med Microbiol 2009;27(3):217-221.

15. Moore DA, Evans CA, Gilman RH, Caviedes L, Coronel J, Vivar A, et al. Microscopic-observation drug-susceptibility assay for the diagnosis of TB. N Engl J Med 2006;355(15):1539-50.

16. Ha DT, Lan NT, Wolbers M, Duong TN, Quang ND, Thi Van Thinh T, et al. Microscopic observation drug susceptibility assay (MODS) for early diagnosis of tuberculosis in children. PLoS One 2009;4(12):e8341.

17. Minion J, Leung E, Menzies D, Pai M. Microscopic-observation drug susceptibility and thin layer agar assays for the detection of drug resistant tuberculosis: a systematic review and metaanalysis. Lancet Infect Dis 2010;10(10):688-698.

18. Dang TM, Nguyen TN, Wolbers M, Vo SK, Hoang TT, Nguyen $\mathrm{HD}$, et al. Evaluation of microscopic observation drug susceptibility assay for diagnosis of multidrug-resistant tuberculosis in Vietnam. BMC Infect Dis 2012;12:49.

19. Escombe AR, Lazarus RP, Kalaiselvan S, John KR, Michael JS. Evaluation of the microscopic observational drug susceptibility assay for rapid and efficient diagnosis of multi-drug resistant tuberculosis. Indian J Med Microbiol 2012;30(1):64-68.

20. Dixit P, Singh U, Sharma P, Jain A. Evaluation of nitrate reduction assay, resazurin microtiter assay and microscopic observation drug susceptibility assay for first line antitubercular drug susceptibility testing of clinical isolates of M. tuberculosis. J Microbiol Methods 2012;88(1):122-126.

21. Lu JM, Wang J, Huang XC, Hu ZY, Cui ZL. Evaluation of microscopic observation drug susceptibility for drug susceptibility testing of Mycobacterium tuberculosis in smear-positive sputum. (Article in Chinese). Zhonghua Yu Fang Yi Xue Za Zhi 2011; 45(1):21-25.

22. Shah NS, Moodley P, Babaria P, Moodley S, Ramtahal M, Richardson J, et al. Rapid diagnosis of tuberculosis and multidrug resistance by the microscopic-observation drug-susceptibility assay. Am J Respir Crit Care Med 2011;183(10):1427-1433.

23. Mendoza A, Castillo E, Gamarra N, Huamán T, Perea M, Monroi Y, et al. Reliability of the MODS assay decentralisation process in three health regions in Peru. Int J Tuber Lung Dis 2011;15(2):217-22.

24. Limaye K, Kanade S, Nataraj G, Mehta P. Utility of microscopic observation of drug susceptibility (MODS) assay for Mycobacterium tuberculosis in resource constrained settings. Indian J Tuber 2010;57(4):207-212.

25. Ha DT, Lan NT, Kiet VS, Wolbers M, Hang HT, Day J, et al. Diagnosis of pulmonary tuberculosis in HIV-positive patients by microscopic observation drug susceptibility assay. J Clin Microbiol 2010;48(12):4573-4579.

26. Flores LL, Steingart KR, Dendukuri N, Schiller I, Minion J, Pai M, et al. Systematic review and meta-analysis of antigen detection tests for the diagnosis of tuberculosis. Clin Vaccine Immunol 2011;18(10):1616-1627.
27. Bogard M, Vincelette J, Antinozzi R, Alonso R, Fenner T, Schirm J, et al. Multicenter study of a commercial, automated polymerase chain reaction system for the rapid detection of Mycobacterium tuberculosis in respiratory specimens in routine clinical practice. Eur J Clin Microbiol Infect Dis 2001;20(10): 724-731.

28. Tonjum T, Klintz L, Bergan T, Baann J, Furuberg G, Cristea M, et al. Direct detection of Mycobacterium tuberculosis in respiratory samples from patients in Scandinavia by polymerase chain reaction. Clin Microbiol Infect 1996;2(2):127-131.

29. Boehme CC, Nabeta P, Henostroza G, Raqib R, Rahim Z, Gerhardt M, et al. Operational feasibility of using loop-mediated isothermal amplification for diagnosis of pulmonary tuberculosis in microscopy centers of developing countries. J Clin Microbiol 2007;45(6):1936-1940.

30. Cormican MG, Glennon M, Riain UN, Smith T, Flynn J, Gannon F. Evaluation of a PCR assay for detection of Mycobacterium tuberculosis in clinical specimens. Diagn Microbiol Infect Dis 1995;22(4):357-360.

31. An Q, Buxton D, Hendricks A, Robinson L, Shah J, Lu L, et al. Comparison of amplified Q beta replicase and PCR assays for detection of Mycobacterium tuberculosis. J Clin Microbiol 1995;33(4):860-867.

32. Walker GT, Nadeau JG, Spears PA, Schram JL, Nycz CM, Shank DD. Multiplex strand displacement amplification (SDA) and detection of DNA sequences from Mycobacterium tuberculosis and other mycobacteria. Nucleic Acids Res 1994; 22(13):26702677.

33. Kang EY, Choi JA, Seo BK, Oh YW, Lee CK, Shim JJ. Utility of polymerase chain reaction for detecting Mycobacterium tuberculosis in specimens from percutaneous transthoracic needle aspiration. Radiology 2002;225(1):205-209.

34. Burggraf S, Reischl U, Malik N, Bollwein M, Naumann L, Olgemoller B. Comparison of an internally controlled, largevolume light cycler assay for detection of Mycobacterium tuberculosis in clinical samples with the cobas amplicor assay. J Clin Microbiol 2005;43(4):1564-1569.

35. Kidane D, Olobo JO, Habte A, Negesse Y, Aseffa A, Abate G, et al. Identification of the causative organism of tuberculous lymphadenitis in ethiopia by PCR. J Clin Microbiol 2002; 40(11):4230-4234.

36. Cho SN. Current issues on molecular and immunological diagnosis of tuberculosis. Yonsei Med J 2007;48(3):347-359.

37. Sharma K, Sharma A, Singh M, Ray P, Dandora R, Sharma SK, et al. Evaluation of polymerase chain reaction using protein $b$ primers for rapid diagnosis of tuberculous meningitis. Neurol India 2010;58(5):727-731.

38. Sharma K, Sarma A, Pallab R, Kumar SS, Manish M, Sudesh P, et al. Multiplex PCR for rapid diagnosis of tuberculous meningitis. J Neurol 2011;258(10):1781-1787.

39. Sharma K, Sharma A, Sharma SK, Sen RK, Dhillon MS, Sharma M. Does multiplex polymerase chain reaction increase the diagnostic percentage in osteoarticular tuberculosis? A prospective evaluation of 80 cases. Int Orthop 2012;36(2):255-259.

40. Sharma K, Gupta V, Bansal R, Sharma A, sharma M, Gupta A. Novel multi-targeted polymerase chain reaction for diagnosis of presumed tubercular uveitis. J Ophthal Inflamm Infect 2013, $3: 25$.

41. Sharma K, Sinha SK, Sharma A, Nada R, Prasad KK, Goyal K, et al. Multiplex PCR for rapid diagnosis of gastrointestinal tuberculosis. J Global infect Dis (In press). 
42. Sharma K, Chopra S, Gupta N, Sharma A, Sharma S, Dhaliwal $\mathrm{L}$, et al. Evaluation of multiplex PCR for rapid diagnosis of female genital tract tuberculosis. Indian J Med Sci (In press).

43. Bhattacharya B, Karak K, Ghosal AG, Roy A, Das S, Dandapat $\mathrm{P}$, et al. Development of a new sensitive and efficient multiplex polymerase chain reaction (PCR) for identification and differentiation of different mycobacterial species. Trop Med Int Health 2003;8(2):150-157.

44. Sharma K, Sharma A, Modi M, Singh G, Kaur H, Varma S, et al. PCR detection of coinfection with Mycobacterium tuberculosis and Mycobacterium avium in AIDS pateints with meningitis. J Med Microbiol 2012;61(Pt 12):1789-1791.

45. Pandey BD, Poudel A, Yoda T, Tamaru A, Oda N, Fukushima Y, et al. Development of an in-house loop-mediated isothermal amplification (LAMP) assay for detection of Mycobacterium tuberculosis and evaluation in sputum samples of Nepalese patients. J Med Microbiol 2008;57(Pt 4):439-443.

46. Mitarai S, Okumura M, Toyota E, Yoshiyama T, Aono A, Sejimo A, et al. Evaluation of a simple loop-mediated isothermal amplification test kit for the diagnosis of tuberculosis. Int J Tuber Lung Dis 2011;15(9):1211-1217.

47. Boehme CC, Nabeta P, Hillemann D, Nicol MP, Shenai S, Krapp $\mathrm{F}$, et al. Rapid molecular detection of tuberculosis and rifampin resistance. N Engl J Med 2010;363(11):1005-1015.

48. Vadwai V, Boehme C, Nabeta P, Shetty A, Alland D, Rodrigues C. Xpert MTB/RIF: a new pillar in diagnosis of extrapulmonary tuberculosis. J Clin Microbiol 2011;49(7): 2540-2545.

49. WHO. Molecular line probe assays for rapid screening of patients at risk of multi-drug resistant tuberculosis (MDR-TB). WHO Expert Group Report 2008:1-33. (Available at: http://www. who.int/tb/features_archive/expert_group_report_june08.pdf.

50. Morgan M, Kalantri S, Flores L, Pai M. A commercial line probe assay for the rapid detection of rifampicin resistance in Mycobacterium tuberculosis: a systematic review and metaanalysis. BMC Infect Dis 2005;5:62.

51. Skenders GK, Holtz TH, Riekstina V, Leimane V. Implementation of the INNO-LiPA Rif. TB $®$ line-probe assay in rapid detection of multidrug-resistant tuberculosis in Latvia. Int J Tuberc Lung Dis 2011;15(11):1546-1552.

52. Al-Mutairi NM, Ahmad S, Mokaddas E. Performance comparison of four methods for detecting multidrug-resistant Mycobacterium tuberculosis strains. Int J Tuberc Lung Dis 2011 15(1):110-115.

53. Bicmen C, Gunduz AT, Coskun M, Senol G, Ozkutuk N, Cirak AK, et al. Molecular identification and characterization of rifampicin-resistant Mycobacterium tuberculosis isolates by line probe assay: an approach for rapid diagnosis of multidrug-resistant tuberculosis. Lett Appl Microbiol 2008; 47(3):214-220.

54. Costeira J, Pina J. Multi-drug resistant tuberculosis and the red queen- diagnosis speed is crucial [Article in Portuguese]. Rev Port Pneumol 2007;13(6):869-877.

55. Ozkutuk N, Gazi H, Surucuoglu S, Gunduz A, Ozbakkaloglu B. Characterization of rpoB mutations by line probe assay in rifampicin-resistant Mycobacterium tuberculosis clinical isolates from the aegean region in Turkey. Jpn J Infect Dis 2007;60(4): 211-213.

56. Quezada CM, Kamanzi E, Mukamutara J, De Rijk P, Rigouts L, Portaels F, et al. Implementation validation performed in Rwanda to determine whether the INNO-LiPA Rif.TB line probe assay can be used for detection of multidrug-resistant Mycobacterium tuberculosis in low-resource countries. J Clin Microbiol 2007; 45(9):3111-3114.

57. Traore H, van Deun A, Shamputa IC, Rigouts L, Portaels F. Direct detection of Mycobacterium tuberculosis complex DNA and rifampin resistance in clinical specimens from tuberculosis patients by line probe assay. J Clin Microbiol 2006;44(12): 4384-4388.

58. Sam IC, Drobniewski F, More P, Kemp M, Brown T. Mycobacterium tuberculosis and rifampin resistance, United Kingdom. Emerg Infect Dis 2006;12(5):752-759.

59. Mäkinen J, Marttila HJ, Marjamäki M, Viljanen MK, Soini H. Comparison of two commercially available DNA line probe assays for detection of multidrug-resistant Mycobacterium tuberculosis. J Clin Microbiol 2006;44(2):350-352.

60. Viveiros M, Leandro C, Rodrigues L, Almeida J, Bettencourt R, Couto I, et al. Direct application of the INNO-LiPA Rif. TB line-probe assay for rapid identification of Mycobacterium tuberculosis complex strains and detection of rifampin resistance in 360 smear-positive respiratory specimens from an area of high incidence of multidrug-resistant tuberculosis. J Clin Microbiol 2005;43(9):4880-4884.

61. Johansen IS, Lundgren B, Sosnovskaja A, Thomsen VØ. Direct detection of multidrug-resistant Mycobacterium tuberculosis in clinical specimens in low- and high-incidence countries by line probe assay. J Clin Microbiol 2003;41(9):4454-4456.

62. Cirillo DM, Piana F, Frisicale L, Quaranta M, Riccabone A, Penati V, et al. Direct rapid diagnosis of rifampicin-resistant $\mathrm{M}$. tuberculosis infection in clinical samples by line probe assay (INNO LiPA Rif-TB). New Microbiol 2004;27(3):221-227.

63. Srivastava K, Das R, Jakhmola P, Gupta P, Chauhan DS, Sharma VD, et al. Correlation of mutations detected by INNOLiPA with levels of rifampicin resistance in Mycobacterium tuberculosis. Indian J Med Res 2004;120(2):100-105.

64. Sharma M, Sethi S, Mishra B, Sengupta C, Sharma SK. Rapid detection of mutations in rpoB gene of rifampicin resistant Mycobacterium tuberculosis strains by line probe assay. Indian J Med Res 2003;117:76-80.

\section{ABOUT THE AUTHORS}

\section{Kusum Sharma (Corresponding Author)}

Associate Professor, Department of Medical Microbiology, Postgraduate Institute of Medical Education and Research, Chandigarh, India e-mail: sharmakusum9@yahoo.co.in

\section{Suma B Appannanavar}

Senior Research Associate, Department of Medical Microbiology Postgraduate Institute of Medical Education and Research Chandigarh, India

\section{Kapil Goyal}

Senior Research Associate, Department of Medical Microbiology Postgraduate Institute of Medical Education and Research Chandigarh, India

\section{Aman Sharma}

Assistant Professor, Department of Internal Medicine, Postgraduate Institute of Medical Education and Research, Chandigarh, India 